\title{
Pengembangan Media Pembelajaran Animasi Pada Materi Fotosintesis untuk Siswa Kelas VIII MTsN Koto Nan Gadang
}

\author{
Sri Nengsi* \\ STKIP Abdi Pendidikan Payakumbuh, \\ Jl. Prof. M Yamin Payakumbuh. Telp. (0752) 93650
}

(Diterima September 2015, Disetujui Desember 2015)

\begin{abstract}
Animated learning media that available in the market or Internet, has so much improvement. However, there is some lacking or flaw in the learning media, such as it is not came with explanation so the teacher need to explain it. And the media show the material too fast or it do not have control button so the students is troubled to understand and the teacher need to rush to explain it. Also the media template do not match with the user. Hence, based from this lacking or flaw the research to develop animated photosynthesis learning media for class VIII students of MTsN Koto Nan Gadang, purposed to make the biology class more attractive, effective and efficient. This research is a method using 4-D model, definition, design, development and disseminating. In development phase, researcher must do validation for the animated learning media, done with 2 validator using validation sheet to see the practicality of the animated learning media, this validation sheet given to the teacher and the student. The data process result from validation and practicality questionnaire is concluded that the developed animated learning media has valid in quality and practical to use by teachers and students, so that suitable to become Biology learning media in photosynthesis subject.
\end{abstract}

Keyword: Animated, Photosynthesis, learning media

\begin{abstract}
ABSTRAK
Media pembelajaran animasi yang tersedia di pasaran atau Internet, memiliki begitu banyak perbaikan. Namun, ada beberapa kekurangan atau kelemahan dalam media pembelajaran, seperti tidak memiliki dengan penjelasan sehingga guru perlu menjelaskannya. Dan media menampilkan materi terlalu cepat atau tidak memiliki tombol kontrol sehingga siswa kesulitan untuk memahami dan guru terburu-buru untuk menjelaskannya. Juga template media yang tidak cocok dengan pengguna. Oleh karena itu, berdasarkan kekurangan atau kelemahan ini penelitian untuk mengembangkan animasi media pembelajaran fotosintesis untuk kelas VIII siswa MTsN Koto Nan Gadang, bertujuan untuk membuat kelas biologi lebih menarik, efektif dan efisien. Penelitian ini adalah metode menggunakan 4-D Model, definisi, desain, pengembangan dan penyebaran. Pada tahap pengembangan, peneliti harus melakukan validasi untuk media pembelajaran animasi, dilakukan dengan 2 validator menggunakan lembar
\end{abstract}


validasi untuk melihat kepraktisan media pembelajaran animasi, lembar validasi ini diberikan kepada guru dan siswa. Hasil pengolahan data dari validasi dan kepraktisan kuesioner disimpulkan bahwa media pembelajaran animasi yang dikembangkan adalah valid dalam kualitas dan praktis untuk digunakan oleh guru dan siswa, sehingga cocok untuk menjadi media pembelajaran Biologi dalam subjek fotosintesis.

Katakunci: Animasi, Fotosintesis, dan Media pembelajaran

\section{PENDAHULUAN}

Dewasa ini ilmu pengetahuan dan teknologi berkembang semakin pesat. Hal tersebut jelas memberikan pengaruh di berbagai bidang termasuk bidang pendidikan. Munib (2004: 34) dalam Daryanto (2010: 1) menyatakan bahwa, pendidikan adalah usaha sadar dan sistematis yang dilakukan orang orang yang diserahi tanggung jawab, untuk mempengaruhi peserta didik agar mempunyai sifat dan tabiat sesuai dengan cita cita pendidikan. Makna pendidikan juga tercantum dalam UU No. 20 Tahun 2003, yang menjelaskan bahwa pendidikan adalah usaha sadar dan terencana untuk mewujudkan suasana belajar dan proses pembelajaran, agar siswa secara aktif mengembangkan potensi dirinya, untuk memiliki kekuatan spiritual keagamaan, pengendalian diri, kepribadian, kecerdasan, akhlak mulia, serta keterampilan yang diperlukan dirinya, masyarakat, bangsa dan negara.

Daryanto (2010: 1) menerangkan bahwa prestasi belajar siswa di sekolah sering diindikasikan dengan permasalahan belajar dari siswa itu sendiri dalam memahami materi. Indikasi ini dimungkinkan karena faktor belajar yang kurang efektif, bahkan siswa tidak merasa termotivasi di dalam mengikuti pembelajaran di kelas. Sehingga menyebabkan siswa kurang atau bahkan tidak memahami materi yang bersifat sukar yang diberikan oleh guru tersebut. Untuk memecahkan masalah belajar atau memfasilitasi kegiatan pembelajaran tersebut digunakan teknologi pembelajaran. Teknologi pembelajaran sebagai perangkat lunak (software technology) yang berbentuk cara-cara yang sistematis dalam memecahkan masalah pembelajaran yang semakin canggih dan mendapat tempat secara luas dalam dunia pendidikan (Suparman \& Zuhairi dalam Warsita, (2008: $10)$. 
Berdasarkan pengamatan penulis, media pembelajaran Biologi yang biasa digunakan oleh guru masih menggunakan media berbasis visual seperti charta dan torso, pembelajaran Biologi dirasa perlu menggunakan media pembelajaran yang dapat mengintegrasikan teks, gambar, serta suara, dan video secara bersamaan seperti media animasi, sehingga pembelajaran Biologi akan lebih menarik, efektif, dan efisien. Berdasarkan hal tersebut maka dilakukan penelitian dengan tujuan untuk mengembangkan media pembelajaran dalam meningkatkan hasil belajar siswa.

Media pembelajaran yang berbentuk animasi, baik yang sudah digunakan oleh guru maupun yang penulis temukan di pasaran atau internet, sudah banyak mengalami perkembangan. Namun, penulis masih menemukan kekurangan atau kelemahan pada media tersebut, diantaranya yaitu: (1) media animasi yang tidak memiliki keterangan, sehingga guru masih perlu menjelaskan lebih lanjut; (2) media animasi yang bergerak terlalu cepat atau tanpa tombol control sehingga siswa sulit memahami media dan guru tergesa-gesa dalam menerangkan materi; (3) template media animasi yang kurang sesuai dengan karakteristik pengguna media animasi.

Sadiman, dkk. (2011: 6) mengungkapkan kata media berasal dari bahasa Latin dan merupakan bentuk jamak dari kata medium yang secara harfiah berarti perantara atau pengantar. Medòë adalah perantara atau pengantar pesan dari pengirim ke penerima pesan. Menurut Criticos (1996) dalam Daryanto (2010: 4) media merupakan salah satu komponen komunikasi, yaitu sebagai pembawa pesan dari komunikator menuju komunikan.

Warsita (2008: 148) merumuskan kegunaan media secara umum, yaitu:

1) Memperjelas pesan agar tidak terlalu verbalistis.

2) Mengatasi keterbatasan ruang, waktu tenaga, dan daya indra.

3) Menimbulkan gairah belajar, interaksi lebih lansung antara murid dengan sumber belajar.

4) Memungkinkan anak belajar mandiri sesuai dengan bakat dan kemampuan visual, auditori dan kinestetikanya.

5) Memberi ransangan yang sama, mempersamakan pengalaman dan menimbulkan persepsi yang sama. 
Proses pembelajaran mengandung lima komponen komunikasi, yaitu guru (komunikator), bahan pembelajaran, media pembelajaran, siswa (komunikan), dan tujuan pembelajaran (Daryanto, 2010: 6).

\section{Macam-macam Media Pembelajaran}

Dalam perkembangannya media pembelajaran mengikuti perkembangan teknologi. Berdasarkan perkembangan teknologi tersebut, Arsyad (2004: 29-33) mengelompokkan media pembelajaran kedalam empat kelompok, yaitu:

\section{a. Media Hasil Teknologi Cetak}

Teknologi cetak adalah cara untuk menghasilkan atau menyampaikan materi, seperti buku dan materi visual statis terutama melalui proses pencetakan mekanis atau fotografis. Materi cetak dan visual merupakan dasar pengembangan dan penggunaan kebanyakan materi pembelajaran lainnya. Teknologi ini menghasilkan materi dalam bentuk salinan tercetak. Teknologi cetak memiliki ciri-ciri sebagai berikut:

1) Teks dibaca secara linear, sedangkan visual diamati berdasarkan ruang;

2) Baik teks maupun visual menampilkan komunikasi satu arah dan reseptif;

3) Teks dan visual ditampilkan statis (diam);

4) Pengembangannya sangat tergantung kepada prinsip-prinsip kebahasaan dan persepsi visual.

5) Baik teks maupun visual berorientasi (berpusat) pada siswa;

6) Informasi dapat diatur kembali atau ditata ulang oleh pemakai.

\section{b. Media Hasil Teknologi Audio-visual}

Teknologi audio visual cara menghasilkan atau menyampaikan materi dengan menggunakan mesin-mesin mekanis dan elektronik untuk menyajikan pesanpesan audio dan visual. Ciri-ciri utama teknologi media audio-visual adalah sebagai berikut : 
1) Media biasanya bersifat linear.

2) Media biasanya menyajikan visual yang dinamis.

3) Media digunakan dengan cara yang telah ditetapkan sebelumnya oleh perancang/pembuatnya.

4) Media merupakan representasi fisik dari gagasan real atau gagasan abstrak.

5) Media dikembangkan menurut prinsip psikologis behaviorisme dan kognitif.

6) Umumnya mereka berorientasi kepada guru dengan tingkat pelibatan interaktif murid yang rendah.

\section{c. Media Hasil Teknologi yang Berdasarkan Komputer}

Teknologi berbasis komputer merupakan cara menghasilkan atau menyampaikan materi dengan menggunakan sumber-sumber yang berbasis mikroprosesor. Perbedaan antara media yang dihasilkan oleh teknologi berbasis komputer dengan media hasil teknologi lainnya adalah karena informasi/ materi disimpan dalam bentuk digital, bukan dalam bentuk cetakan. Berbagai jenis aplikasi teknologi berbasis computer dalam pembelajaran umumnya dikenal sebagai computer-assisted instruction (pembelajaran dengan bantuan komputer).

Aplikasi tersebut apabila dilihat dari cara penyajian dan tujuan yang ingin dicapai meliputi tutorial (penyajian materi secara bertahap), drills and practice (latihan untuk membantu siswa menguasai materi yang telah dipelajari sebelumnya), permainan dan simulasi (latihan mengaplikasikan pengetahuan dan keterampilan yang baru dipelajari), dan basis data (sumber yang dapat membantu siswa menambah informasi dan pengetahuan sesuai dengan keinginan masingmasing).

\section{d. Media Hasil Gabungan Teknologi Cetak dan Komputer}

Teknologi gabungan adalah cara untuk menghasilkan dan menyampaikan materi yang menggabungkan pemakaian beberapa bentuk media yang dikendalikan oleh komputer. Beberapa ciri utama teknologi berbasis komputer adalah sebagai berikut: 
1) Media dapat digunakan secara acak, sekuensial, secara linear.

2) Media dapat digunakan sesuai dengan keinginan siswa, bukan saja dengan cara yang direncanakan dan diinginkan oleh perancangnya.

3) Media gagasan-gagasan sering disajikan secara realistik dalam konteks pengalaman siswa, menurut apa yang relevan dengan siswa, dan di bawah pengendalian siswa.

4) Prinsip ilmu kognitif dan konstruktivisme diterapkan dalam pengembangan dan penggunaan pembelajaran.

5) Pembelajaran ditata dan terpusat pada lingkup kognitif sehingga pengetahuan dikuasai jika pelajaran itu digunakan.

6) Bahan-bahan pelajaran melibatkan banyak interaktivitas siswa.

7) Bahan-bahan pelajaran memadukan kata dan visual dari berbagai sumber.

\section{e. Media Animasi}

Animasi menggambarkan objek yang bergerak agar kelihatan hidup. Membuat animasi berarti menggerakkan gambar seperti, kartun, lukisan, tulisan, dan lain- lain (Sutopo, 2002: 2). Vaughan (2006: 161) juga mengemukakan animasi merupakan perubahan visual sepanjang waktu dan memberi kekuatan besar pada proyek multimedia.

Animasi sudah sejak lama dikenal oleh masyarakat. Menurut Gora (2004: 1) animasi mulai dikenal akrab sejak populernya media televisi yang dapat menyajikan gambar bergerak hasil rekaman kegiatan makhluk hidup, manusia, atau hewan. Dibandingkan gambar foto yang diam atau tidak bergerak, televisi jelas lebih disukai karena dapat lebih membangkitkan antusiasme dan emosi penonton.

\section{METODE PENELITIAN}

Model yang digunakan dalam pengembangan adalah model 4-D (four D), yang terdiri dari 4 tahap. Thiagarajan, dkk dalam Trianto (2012: 189) menyatakan bahwa, tahap-tahap itu adalah: pendefinisian (define), perancangan (design), pengembangan (develop) dan penyebaran (disseminate). 


\section{HASIL dan PEMBAHASAN}

\section{Validasi media pembelajaran animasi}

Validasi media pembelajaran animasi dilakukan oleh 2 orang validator menggunakan lembar validasi, hasil dapat di lihat pada Tabel 1.

Tabel 1. Hasil Validasi Media Pembelajaran Animasi

\begin{tabular}{clcccl}
\hline \multirow{2}{*}{ No. Aspek } & & \multicolumn{2}{c}{ Validasi $(\%)$} & Total & Kategori \\
\cline { 3 - 4 } & & 1 & 2 & $(\%)$ & \\
\hline 1 & Materi/syarat didaktik & 91,7 & 86,1 & 88,9 & Sangat valid \\
2 & Konstruksi & 95 & 85 & 90 & Sangat valid \\
3 & Teknis & 87,5 & 83,3 & 85,4 & Sangat valid \\
& Rata-rata & & & 88,1 & Sangat valid \\
\hline
\end{tabular}

Berdasarkan hasil validasi media pembelajaran animasi yang ditampilkan pada Tabel 1. menghasilkan persentase sebesar $88,1 \%$, tergolong dalam kriteria sangat valid. Hal ini berarti media pembelajaran animasi yang dikembangkan sudah valid kualitasnya untuk dijadikan media pembelajaran Biologi pada pokok bahasan fotosintesis, ditinjau dari aspek materi, konstruksi, dan teknis.

Validator melakukan penilaian terhadap media pembelajaran animasi. Ternyata, masih banyak kesalahan dan kekurangan yang ditemukan di dalam media pembelajaran animasi tersebut. Sesuai dengan saran dari validator, penulis melakukan perbaikan hingga media pembelajaran animasi divalidasi dan layak untuk digunakan. Hal ini sejalan dengan pendapat Angkowo \& Kokasih (2007: 10), yang menyebutkan bahwa media pembelajaran yang diprogram dengan baik, seperti $C D$ akan mampu mengarahkan siswa sesuai dengan motivasi dan kemampuannya.

Sebagaimana yang diungkapkan oleh Angkowo \& Kokasih (2007: 12), dalam memilih media pembelajaran perlu memperhatikan tiga hal, yaitu: kejelasan maksud dan tujuan media, sifat dan ciri-ciri media yang dipilih, adanya sejumlah media yang dibandingkan. Dengan demikian, berdasarkan hasil analisis angket validasi diatas dapat disimpulkan, media pembelajaran animasi yang dikembangkan sudah valid kualitasnya, untuk dijadikan media pembelajaran Biologi pada pokok bahasan fotosintesis. 


\section{Praktikalitas media animasi}

Praktikalitas media pembelajaran animasi, yaitunya dengan menggunakan lembar angket respon yang diberikan pada guru dan siswa. Berikut akan ditampilkan hasil praktikalitas media pembelajaran animasi.

\section{a. Praktikalitas media pembelajaran animasi oleh guru}

Tabel 2. Hasil Animasi. Praktikalitas Respon Guru terhadap Media Pembelajaran

\begin{tabular}{cccc}
\hline No & Variabel & $(\%)$ & Kriteria \\
\hline 1 & Kemudahan Penggunaan & 100 & Sangat Praktis \\
2 & Waktu & 100 & Sangat Praktis \\
3 & Penampilan & 100 & Sangat Praktis \\
& Rata-rata & 100 & Sangat Praktis \\
\hline
\end{tabular}

Berdasarkan hasil analisis angket praktikalitas oleh guru mengenai media pembelajaran animasi yang dikembangkan menghasilkan persentase sebesar 100 $\%$ yang tergolong dalam kriteria sangat praktis. dari segi praktikalitas media pembelajaran yang dikembangkan, menarik dan dapat memotivasi siswa dan mudah dioperasikan sehingga layak untuk dijadikan media pembelajaran biologi pada pokok bahasan fotosintesis. Imayanti (2009: 1) juga menyampaikan dalam suatu penelitian disebutkan bahwa pentingnya animasi sebagai media pembelajaran adalah memiliki kemampuan untuk memaparkan suatu yang rumit atau komplek serta sulit dijelaskan dengan hanya gambar atau kata-kata saja. Dengan kemampuan ini maka media animasi pembelajaran dapat digunakan untuk menjelaskan materi secara nyata.

\section{b. Praktikalitas media pembelajaran animasi oleh siswa}

Tabel 3. Hasil Praktikalitas Media Pembelajaran Animasi oleh Siswa

\begin{tabular}{clcl}
\hline No & \multicolumn{1}{c}{ Variabel } & $(\%)$ & \multicolumn{1}{c}{ Kriteria } \\
\hline 1 & Bahasa & 89,9 & Sangat praktis \\
2 & Kemudahan penggunaan & 81,1 & Sangat praktis \\
3 & Minat dan motivasi & 78,8 & Praktis \\
4 & Penampilan & 85,6 & Sangat praktis \\
& Rata-rata & 83,85 & Sangat praktis \\
\hline
\end{tabular}


Berdasarkan hasil analisis angket praktikalitas oleh siswa mengenai media pembelajaran animasi yang dikembangkan menghasilkan persentase sebesar 83,85 $\%$ yang tergolong dalam kriteria sangat praktis. Hal ini berarti, dari segi praktikalitas media pembelajaran yang dikembangkan, media pembelajaran animasi menarik dan dapat memotivasi siswa dan mudah dioperasikan sehingga layak untuk dijadikan media pembelajaran Biologi pada pokok bahasan fotosintesis.

Angket praktikalitas yang diberikan kepada guru dan siswa memperoleh penilaian yang baik, walaupun demikian, ada beberapa hal yang harus penulis tambah dan perbaiki, agar media animasi ini menjadi benar-benar dapat dikonsumsi oleh siswa dengan baik. Sebagaimana yang disarankan oleh guru, yaitu tumbuhan dikatakan organime dipermukaan bumi ini, agar penjelasan dalam penyampaian materi lebih dikembangkan, dan unsur penting dalam fotosintesis, bagaimana hasil fotosintesis itu digunakan, dan disimpan dalam bentuk apa, dan penjelasan faktor yang mempengaruhi agar lebih dikembangkan, kalau faktor kurang apa akibatnya begitu pula sebaliknya. Penulis tinggal menambahkannya saja agar lebih sempurna, dasar-dasarnya sudah bagus.

\section{KESIMPULAN}

Berdasarkan hasil penelitian dan pembahasan maka dapat dikemukakan simpulan penelitian sebagai berikut.

1. Media pembelajaran animasi yang dikembangkan pada materi fotosintesis untuk siswa kelas VIII MTsN Koto Nan Gadang valid digunakan dalam pembelajaran.

2. Media pembelajaran animasi yang dikembangkan pada materi fotosintesis untuk siswa kelas VIII MTsN praktis digunakan dalam pembelajaran 


\section{DAFTAR PUSTAKA}

Angkowo, R., \& Kokasih, A. 2007. Optimalisasi Media Pembelajran. Jakarta: PT. Grasindo.

Arsyad, Azhar. 2004. Media Pembelajaran. Jakarta: PT. Grafindo Persada.

Daryanto. 2010. Media Pembelajaran. Yogyakarta: GavaMedia.

Gora, Winastwan. 2004. Animasi 3D Instant Menggunakan Ulead Cool 3D Studio. Yogyakarta: Andi.

Imayanti , Erly Nurul. 2009. Pemanfaatan Media Animasi Pembelajaran Matematika Materi Bangun Ruang Sisi Lengkung Bagi Siswa Kelas IXF SMPN 1 Balongbendo TA 2009 - 2010[Skripsi].

Sadiman, Arif S, dkk. 2011. Media Pendidikan: Pengertian, Pengembangan, dan Pemanfaatannya. Jakarta: Raja Grafindo Persada.

Sutopo, Ariesto Hadi. 2002. Animasi dengan Macromedia Flash. Yogyakarta: Graha ilmu.

Trianto. 2012. Mendesain Model Pembelajaran Inovatif-Progresif. Jakarta: Kencana.

Vaughan, Tay. 2006. Multimedia: Making it Work Edisi 6 .Yogyakarta : Andi.

Warsita, Bambang. 2008. Teknologi Pembelajaran Landasan dan Aplikasinya. Jakarta: Rineka Cipta 